\title{
Optimal operation of a rail lubrication device with respect to noise reduction and wheel/rail friction coefficient
}

\author{
G. Csortos ${ }^{1, *}$, F. Augusztinovicz ${ }^{2}$, P. Bocz ${ }^{1}$ \\ ${ }^{1}$ Budapest University of Technology and Economics, \\ Department of Highway and Railway Engineering \\ Müegyetem rkp. 3. (K. MF98), H-1117 Budapest, Hungary \\ ${ }^{2}$ Budapest University of Technology and Economics, \\ Department of Networked Systems and Services \\ Magyar tudósok krt. 2. (IE. 456), H-1117 Budapest, Hungary \\ *e-mail: csortos.gabriella@emk.bme.hu
}

Submitted: 27/01/2021; Accepted: 27/02/2021; Published online: 11/03/2021

Abstract: During research work, three series of studies were performed to support the importance of using rail lubrication at tramway tracks in Budapest. The first task was to determine the noise reduction efficiency of automated rail lubrication: noise measurements were performed in case of lubricated rails with corrugations, non-lubricated rails with corrugations, grinded rails as well as grinded and lubricated rails. Once the conformity was determined, an additional task was to find the right lubricant. After the noise and braking effect tests of various lubricants, it was a legitimate need to determine the optimum lubricant application because the setting of the devices is based only on the experience of the Operator. Finally, the noise mitigation effect and the friction coefficient affecting the wheel/rail contact with different lubricant application settings were investigated simultaneously. It is important that the lubricant be applied in appropriate amount such that even the safe movement of the trams is guaranteed, but at the same time the noise reduction is satisfactory too. Based on the results, the authors make recommendations for the application of the rail lubrication devices.

Keywords: tramway; rail lubrication; noise reduction; rail roughness;

friction coefficient; rail grinding 


\section{Introduction}

One of the most important aspects of railway transportation is the environmentalfriendly service and operation, but beside them the cost and energy efficiency, the relatively low life cycle costs have also high significance. Some related modern technologies can be mentioned: reduction of ballast particle degradation and connected studies [1]; development of high-tech materials for lowering plastic track settlements and improvement of drainage [2]; development of more precise mathematical methodologies for calculation of corrections of geometrical irregularities of railway tracks [3]; etc. The authors of this paper also deal with special, modern technology, the so-called noise reduction with rail lubrication device that has a very significant environmental and environment protection importance.

In curves, as the vehicle is guided by the flanges, undesirable and disturbing noise is generated which is typically the wheel squeal. Rail lubrication reduces the formation of the wheel and rail wears and mitigates the noise effect, generated by uneven wears and dynamic wheel-rail contact. Nowadays, rail lubrication devices are used to automate and control the lubrication process. In Hungary, various types of rail lubrication systems have already been installed, usually at small radius curves. However, their operation is based solely on the experience of the Operator.

Our research had three main goals which are achieved by performing three different series of measurements on tramways. First of all, to establish that the automated rail lubrication devices used in Budapest can effectively reduce the sound pressure levels caused by trams in small radius curves. Once the suitability of the devices has been proven, the next step was to find the lubricant with which the procedure of rail lubrication was the most effective. Finally, with the knowledge of appropriate equipment and lubricant, it was necessary to determine the amount of lubricant with which rail lubrication devices could be operated cost-effectively, safely (i.e., without affecting the braking performance of trams), as well as satisfactorily in terms of noise reduction.

The three series of measurements were based on simple noise measurements. The results, conclusions and suggestions of the research were determined by a practical method, data collection and accurate evaluation of the values. By comparing the results, the real values of the noise mitigation achieved by the automated rail lubrication can be obtained. The tests proved that the rail lubrication have adequate noise mitigation effect, and the tests of lubricants confirmed that the efficiency of the lubricant does not depend on the type of it. To determine the optimal dosage of lubricant, noise and friction coefficient tests were required simultaneously. It can be stated that although the amount of lubricant required for acceptable noise reduction affects the coefficient of friction, the values recommended in the literature were still measurable. 


\section{Noise, roughness, and friction coefficient}

The rail lubrication devices are usually installed on curved tracks. Depending on the requirements, the lubrication bars or in some cases only bores deposit the lubricant precisely at the right positions on the rails. Various types of lubrication devices and many lubricants are used, such as greases and oils, which have different compositions to reduce the rail and wheel wears and mitigate the rolling noise (especially squealing noise effects) from the direct wheel-rail contact.

According to [4] rolling noise is generated by surface irregularities on the wheel and/or rail running surface which roughnesses cause vibration, hence wheel and rail vibrations radiate noise. The linearity of the relationship between wheel and rail surface roughness and rolling noise was also established [5]. If the surface roughness is reduced, the rolling noise is also mitigated. Various rail lubrication devices can provide a solution for noise and rail roughness mitigation, but the consequences need to be taken into consideration. As a result of rail lubrication, the values of the friction coefficient in the wheel/rail contact clearly decrease, which leads to slips, wheel spin and an increase in the braking distance.

It is now generally agreed that the coefficient of kinetic friction only depends on the nature of the surfaces. Considering Coulomb's law, the adhesion force is limited by friction coefficient and wheel load of the driven wheel [6]. The friction coefficient between wheel and rail is an important parameter that determines the braking performance of trams, and friction plays a key role in noise generation too. The mechanism based on Hertz theory can be learned from [6] and calculated typical creep force-creepage relationships are shown [7].

Based on [8], which focuses on the friction, wear and lubrication of the wheel-rail contact zone $\left(\sim 1 \mathrm{~cm}^{2}\right)$, the ideal friction coefficients in the wheel-rail contact are $0.25<\mu<0.4$ at running surfaces and $\mu<0.1$ at gauge corner of the high (outer) rails. Summarizing the presented examples, in general, the coefficient of friction of non-lubricated rails under dry conditions is $0.5-0.7$ and varied between $0.25-0.45$ under lubricated conditions.

When a high viscosity material is used, the value of the friction coefficient can fall below 0.1 , for example in case of oils, but it can also drop drastically in case of freezing. There is also an example of the effect of the use of oils [9], where the slip of the wheels of vehicles is certain, since the value of the coefficient of friction was measurable well below 0.1. There are several studies on how traffic is affected and disrupted by water or falling leaves in autumn [10]. However, the applicability of natural lubrication (leaves and humidity) has also been investigated [11]. The boundary friction coefficient was estimated in range of 0.2-0.45 under wet conditions [12], which is the same as lubrication ranges in other publications. 


\section{Measurement processes and conditions}

In the course of our research work, three series of measurements were performed to support the importance of using rail lubrication at tramway tracks in Budapest. During the first measurement the efficiency of the rail lubrication equipment was determined, at the second the suitable lubricant, and at the last one the optimal amount of lubricant. The summary of the tests is shown in Table 1.

Table 1. Summary of the three series of measurements

\begin{tabular}{|l|l|}
\hline \multicolumn{2}{|l|}{ I. EFFICIENCY OF RAIL LUBRICATION DEVICE } \\
\hline Purpose: & $\begin{array}{l}\text { To determine the noise reduction efficiency of } \\
\text { an automated rail lubrication }\end{array}$ \\
\hline Measurements: & Noise measurements \\
\hline Instruments: & Class 1 Larson Davis System 824 sound pressure level meter \\
\hline Recorded data: & $\begin{array}{l}\text { Lubricated rails (17 Tatra / 11 CAF) } \\
\text { Diminishing effect of lubrication (11 Tatra / 6 CAF each day) } \\
\text { Non-lubricated rails (19 Tatra / 14 CAF) } \\
\text { Grinded rails (33 Tatra / 18 CAF) } \\
\text { Grinded and lubricated rails (17 Tatra / 12 CAF) }\end{array}$ \\
\hline II. TYPE OF LUBRICANT \\
\hline Purpose: & To find the right lubricant \\
\hline Measurements: & Noise and braking performance measurements \\
\hline Instruments: & $\begin{array}{l}\text { Class 1 Larson Davis System 824 sound pressure level meter } \\
\text { XL Meter deceleration meter }\end{array}$ \\
\hline Recorded data: & $\begin{array}{l}\text { Non-lubricated rails (4x Tatra / CAF / Hanover) } \\
\text { Lubricated (with type A lubricant) rails (4x Tatra / CAF / Hanover) } \\
\text { Non-lubricated rails (4x Tatra / CAF / Hanover) } \\
\text { Lubricated (with type B lubricant) rails (4x Tatra / CAF / Hanover) } \\
\ldots \text { (7 various types of lubricants) }\end{array}$ \\
\hline III. AMOUNT OF LUBRCANT \\
\hline Purpose: & To determine the optimum lubricant application \\
\hline Measurements: & Noise and friction coefficient measurements \\
\hline Instruments: & $\begin{array}{l}\text { Class 1 Larson Davis System 824 sound pressure level meter } \\
\text { TriboRoll friction measuring device }\end{array}$ \\
\hline Recorded data: & $\begin{array}{l}\text { 20\% amount of lubricant (16 Tatra / 13 CAF) } \\
40 \% \text { amount of lubricant (9 Tatra / 10 CAF) } \\
60 \% \text { amount of lubricant (12 Tatra / 11 CAF) } \\
80 \% \text { amount of lubricant (15 Tatra / 16 CAF) }\end{array}$ \\
\hline
\end{tabular}


The first and the third measurements were performed at small radius curves on tram line 17 under an overpass, which is between the station Budafok kocsiszín and Savoya Park end station (Fig. 1). The measuring site was not acoustically appropriate and did not meet the conditions for free space specified in the standard [13] because of the overpass. However, the background noises were minimized, so only the noise of the passing trams could be measured clearly. It is important to note that the measurements can only be compared with themselves. Only the outer track of the curve was examined.

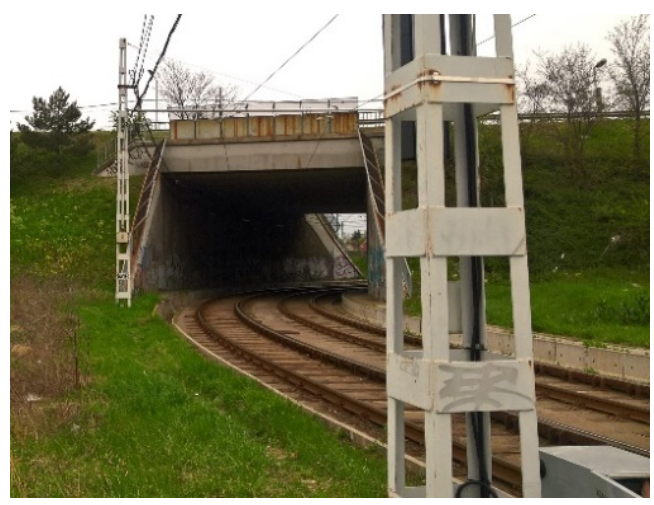

Figure 1. Examined curves between Budafok kocsiszín and Savoya Park stations

The conditions of the measurement were reported in detail [14]. During the tests, a speed limit of $20 \mathrm{~km} / \mathrm{h}$ was in effect. The rail lubrication device was installed at the beginning of the curve. The lubricant is applied to the rails through four bores in the rail heads. On the external rails, two bores on the gauge corner of the railhead, on the inner rails one bore on the running surface and one bore on the guide (check) rails provide lubrication. Two types of vehicles are running on the line: the nearly 40-year-old, Czechoslovakian-made ČKD Tatra T5C5 (hereinafter referred to as Tatra) and the new, short (34 meters long), Spanish-made CAF Urbos 3 trams (hereinafter referred to as CAF).

For simultaneous testing of noise and braking performance by using different lubricants, the chosen site was a service track connecting tram lines 42 and 50 in Budapest. The vertical grade of the track is almost $0 \%$. There was suitable straight section available to measure the braking effect after an arc with a radius of $25 \mathrm{~m}$. The measuring point was set at 7.5 meters from the centre line of the curve and the microphone vertically 1.2 meters from top of the rail (Fig. 2). 


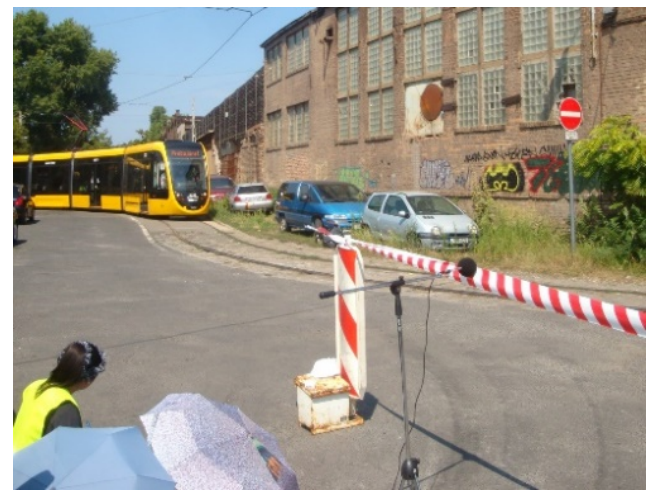

Figure 2. The examined curve on service track and the measuring point

The maximum speed in the curve was $15 \mathrm{~km} / \mathrm{h}$, in the straight section $40 \mathrm{~km} / \mathrm{h}$. The place where the braking starts, and the required braking distance were premeasured. Braking was started by the driver at the designated point, then compliance with the prescribed braking distance was established. In addition to the CAF and Tatra trams, a more than 40-year-old, Germany-made TW 6000 tram (hereinafter referred to as Hanover) was also part of the study. The same three trams were examined on different measurement days. To perform the noise measurements, the road traffic was stopped while the trams were running. The effect on the braking performance of three different types and ages of trams and the extent of noise reduction in a small radius curve were quantified.

During the braking effect test, the data were recorded on the trams with a deceleration meter type XL Meter. The braking distance of the trams was measured, according to safety regulations, before the test and it was marked on the tramway. The recorded values were checked with a measuring wheel with which the distance accurate from the prescribed braking distance to stopped trams was measured. However, compliance with the stopping distance could also be visually proven.

Devices for measuring the friction coefficient are commonly referred to as tribometers. For the third measurement, the TriboRoll friction measuring device was used, which was developed by a Hungarian company, Metalelektro Measuring Technique Ltd. in 2019. The device consists of a measuring frame and a measuring unit with a variable position (5 different angles on the rail head) inside the frame. Friction measurements during the tests only at $90^{\circ}$ (running surface) and $45^{\circ}$ (gauge corner) to the rail were made. The measuring software of the TriboRoll calculates friction coefficient from the measured forces. A handheld surface roughness meter type PCE-RT 1200 was used to determine the surface roughness of rails. Each device helps set the optimum lubrication of the rails. 
The noise measurements were performed with Class 1 Larson Davis System 824 sound pressure level meter, which was calibrated. The instrument measured LAeq values in each second during the passing trams. From these time series energy equivalent sound pressure levels were derived based on the relevant standard method [15], representing each train pass by one single $\mathrm{dB}(\mathrm{A})$ value.

Several consequences can be drawn by evaluating the performed noise measurements. The noise reduction results of rail lubrication device and grinding can be quantified. The results can show the transient effect of noise mitigation by eliminating lubrication process. The lower noise emission of trams running on lubricated rails without rail surface defects can be proven. The effect of different lubricants on noise reduction and stopping distance can be easily compared. By changing the dosage, the results show what the right amount of lubricant is with what trams can drive safely, but the resulting noise levels are also tolerable.

\section{Measurements}

\subsection{Noise mitigation}

In the course of our research work noise tests were accomplished in case of corrugated and lubricated/non-lubricated rails, grinded rails as well as grinded and lubricated rails on a tramline for 13 days. By comparing the results, the real value of the noise mitigation achieved by the rail lubrication device and grinding can be obtained. The diminishing effect of noise mitigation by switching off the units and the effect of grinding on the efficiency of the lubrication were investigated.

The measurements were carried out during summer 2017, on different days, but in the same time interval, at approximately the same temperature, in sunny, windless, or mildly windy weather and at the same measuring point. The measuring point was set at the connection of the two circular curves (approximately in the middle of the underpass), at 2.5 meters from the centre line of the left (inner) track. The microphone was set vertically 1.2 meters from top of the rail.

For the first two days, the results of corrugated and lubricated rails were recorded. This was a test under normal operating conditions. Subsequently, the rail lubrication device was switched off to determine the diminishing noise reduction effect and the time when the lubricant layer disappears from the rails and the undesired noise effects return. After degreasing and cleaning the rails, the condition of the nonlubricated rails was measured for two days.

On the railheads there was significant corrugation, therefore grinding work was intended to remove them with AT VM 8000-12 Extended type grinding machine. The machine removed the corrugations from the railheads, but the worn profiles 
remained unchanged. The grinded rails were measured for three days. To prepare for the last test, the rail lubrication device was switched on to operate. About a month after grinding, the results of the grinded and lubricated rails were record for two day as well.

Fig. 3 shows the summary result of noise measurements. The results represent all tram passing by one single $\mathrm{dB}(\mathrm{A})$ value per rail condition for each day. The noise reduction values are given in relation to the result of the non-lubricated rails. It can be stated that all three measures - lubrication, grinding as well as lubrication and grinding combined - have noise reduction effect.

It was foreseeable that the Tatra trams would cause higher sound pressure levels than the CAF trams. The results show that the attenuating effects of methods are lower for CAF trams, although the results are positive. If the rails with corrugations are either grinded or lubricated, almost the same noise reduction results can be recorded. According to the test, the appropriate noise reduction on the tramway tracks can be achieved by using both methods together.

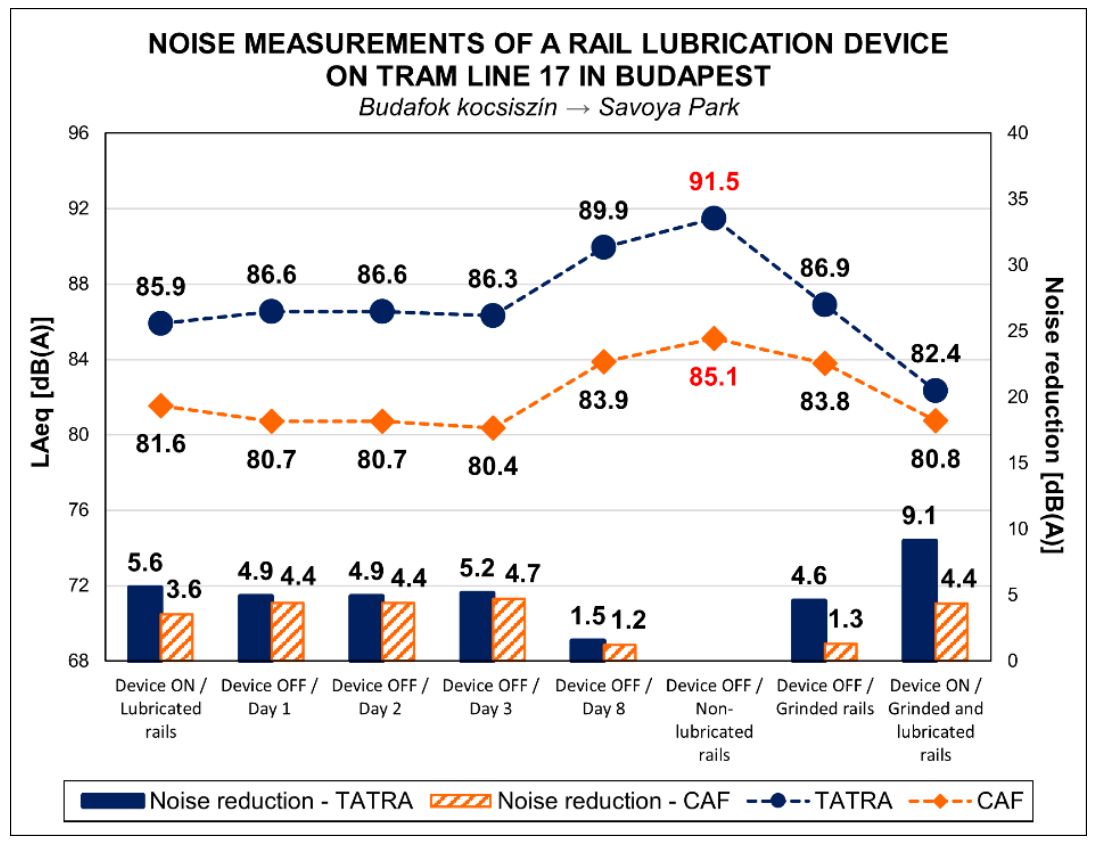

Figure 3. Results of noise measurements of a rail lubrication device on tram line 17 in Budapest 
It can be read from the graph that there is no significant change (only a minimal decrease) in the noise levels in the three days after the rail lubrication device was switched off. The differences are not really outstanding. It can be assumed, that the remaining lubricant layer still had reduction effect or the different trams may have affected the results. The evaluation of the results includes the fact that different trams ran on the measurements days. Significant differences were experienced on day 8, which means that by discontinuing lubrication it takes about a week for the unpleasant noise effects to return.

As expected, the maximum values were recorded on days when non-lubricated rails were examined. These values were reduced by grinding, thereby the importance of grinding work was also proven. It is an encouraging result that the two methods are so effective together that the values of the two trams were approaching each other. While with lubricated rails and non-lubricated rail the differences were $4.3 \mathrm{~dB}(\mathrm{~A})$ and $6.4 \mathrm{~dB}(\mathrm{~A})$ respectively, finally just $1.6 \mathrm{~dB}(\mathrm{~A})$ was gained.

\subsection{Type of lubricant}

It has also been numerically proved that the noise effects in small radius curves can be reduced by rail lubrication. The next task was to find the right lubricant. Therefore, in August and September 2018, noise and brake tests of trams were performed using various lubricants offered by different manufacturers. The purpose of the tests was to identify the lubricants suitable for filling stationary track-side lubrication devices which do not affect the braking performance of trams (i.e., the trams can stop within the prescribed braking distance) but also result in adequate noise reduction. The conditions were planned to test several lubricants with different compositions. Noise levels were recorded at the small radius curve and braking performance measurements in the straight section by passing and stopping the three type of trams (CAF, Tatra, Hanover) Each measurement day one lubricant was tested. The tests were performed in sunny, dry, and windless weather.

Three tests were performed, each in case of non-lubricated and lubricated rails, and before that one test run was also recorded with the trams. The total of 4 nonlubricated and 4 lubricated recorded data per tram were thus measurable on each day. Lubrication of the rails was accomplished, on the one hand, by manual application due to the use of different lubricants and on the other hand due to the short time between tests, as the real layer of lubricant applied from the equipment could not have been recovered. An important aspect was to get as close as possible to simulate the layer applied by automated lubrication. An amount of $1 \mathrm{ml} / \mathrm{meter}$ was applied by hand to the running surface and gauge corner of the rails after the nonlubricated tests. However, a double dose of type A lubricant was also used. At the end of each measurement day, the rails were cleaned. 
Fig. 4 shows the total results per measurement day, the average noise reduction values of the lubricants. Manufacturers of lubricants are not published. The tests were performed jointly with the Budapest Transport Privately Held Corporation, BKV (hereinafter referred to as Operator), the results are known and available for them.

During the series of lubricant tests, there was usually no squealing at the passing of the trams, even with non-lubricated rails. In the absence of outstanding values, the effect of lubrication is not significant on those test days. The different values of non-lubricated condition were caused by the squealing noise levels that occurred during occasional passing. There was a detectable squeal noise on two days.

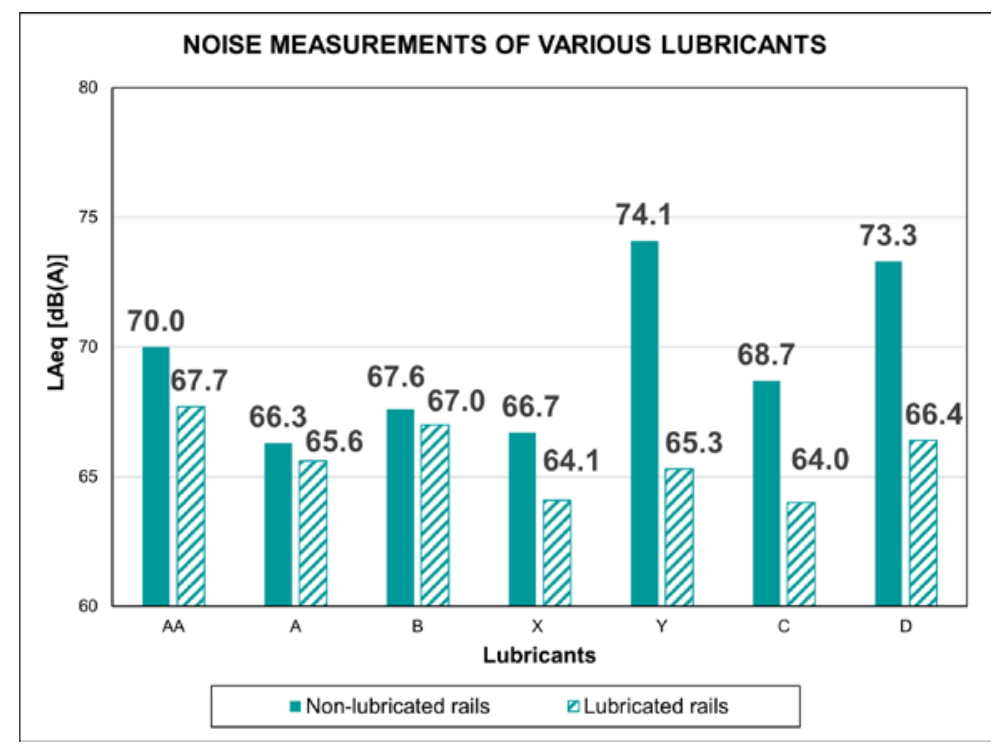

Figure 4. Noise reduction results of the examined lubricants

From the values shown in the above graph, it can be stated that regardless of which lubricant is used, the mitigated results are reduced to almost the same level. The reduced value is on average $65.7 \mathrm{~dB}(\mathrm{~A})$ and the standard deviation is $1.3 \mathrm{~dB}(\mathrm{~A})$. The results also show that double amount of lubricant can reduce the noise level to a similar value. As you can see, remarkable damping values of 8.8 and $6.9 \mathrm{~dB}(\mathrm{~A})$ were obtained with the use of lubricants $\mathrm{Y}$ and $\mathrm{D}$. The aggregate results per tram are summarized in Table 2. The results are interesting, as there was no effect on noise of Hanover by lubrication. The noisiest tram is again the Tatra, and thanks to the lubricants, the CAF tram travels with the lowest noise level. 
Table 2. Aggregate noise reduction results per trams

\begin{tabular}{|c|c|c|c|}
\hline Trams & $\begin{array}{c}\text { Non-lubricated rails } \\
{[d B(A)]}\end{array}$ & $\begin{array}{c}\text { Lubricated rails } \\
{[d B(A)]}\end{array}$ & $\begin{array}{c}\text { Difference } \\
{[d B(A)]}\end{array}$ \\
\hline CAF & 68.3 & 63.5 & -4.9 \\
\hline TATRA & 71.0 & 67.4 & -3.7 \\
\hline HANOVER & 66.9 & 66.6 & -0.3 \\
\hline
\end{tabular}

The trams were able to stop at $80 \%$ of the required braking distance with nonlubricated rails. As expected, the braking distance increased due to lubrication, but not to a significant degree of safety risk. The trams stopped within the specified distance (approx. at 90\%) when using any type of lubricant. However, with the double dosage of the A type lubricant, the trams could no longer meet the requirements: they exceeded the determined value by an average of $3 \%$.

\subsection{Amount of lubricant}

Currently, rail lubrication equipment used on the tram network is based on Operator experience, so there is a legitimate need to set the optimum lubricant application. In 2019, noise measurements were performed at the same site, under the same conditions and with the same method as the first test was conducted to determine the optimal amount of lubricant [16]. From an operational point of view, it is important to require the dosage by which rail lubricator devices can be operated economically and without loss. Primary consideration is that safety is ensured under all circumstances, accompanied by satisfactory level of noise reduction.

The amount and frequency of lubricant application can be changed with three settings. Lubrication events can be varied with the number of passing axles which are detected by the sensor, the length of dosing pump operation can be adjusted, and finally, with the axle counter and dosing pump operation set, the lubricant dosing level can be selected. The sensor mounted on the rail detects the wheels of the vehicles and sends a signal to the control of the device. The control unit is in a cabinet next to the track and it controls the equipment itself. The lubricant container, from which the grease is dosed with a pump is also placed in the cabinet. The dosing pump is started, and the set amount of grease is delivered to the lubrication bores which deposit the lubricant at the rails. Distribution of the lubricant is carried out by the movement of the wheels thus creating an even grease film on the surface of the rails. 
The rails were grinded three weeks before the measurements. To perform the first test, the rail lubrication device was set by the Operator to a $20 \%$ lubrication level. Lubricant was applied after each tram with the dosing pump which operating for 8 seconds. The sensor and dosing pump operating parameters have not been set during the different lubrication stages. The maximum dosing of the lubricant (100\% operation) means $1.4 \mathrm{~cm}^{3}$ per bores, for a total of $5.6 \mathrm{~cm}^{3}$ per tram. Noise, roughness, and friction measurements were performed at 20, 40, 60 and $80 \%$ on different days. At the suggestion of the Operator, the $100 \%$ dosage was not measured for safety reasons, because the traffic could not be disturbed under any circumstances. One week elapsed between the test days. The noise results with different settings of lubrication device presented in Fig. 5.

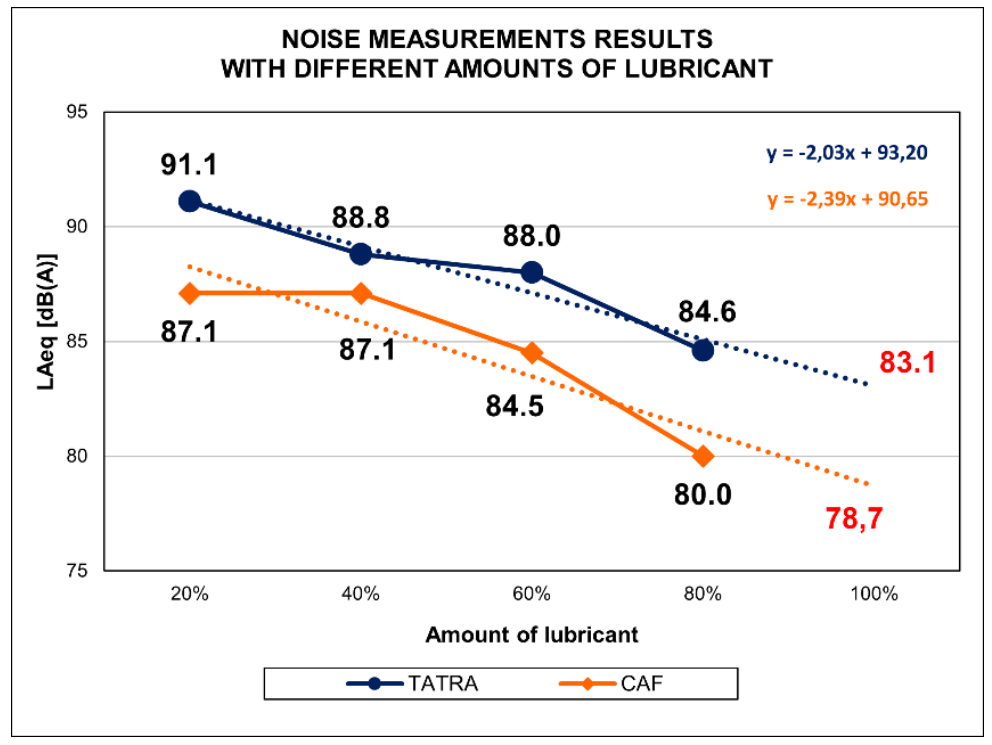

Figure 5. $\quad$ Noise measurement results with different settings of the rail lubrication device

Fig. 5 clearly shows a decreasing trend and again it could be said that the noise levels caused by Tatra trams are higher. The results show the total value of all trams passed on the test day. Furthermore, it can be definitely stated that the more lubricant is applied to the rails, the greater noise reduction can be achieved. There is an average reduction of $2.3 \mathrm{~dB}(\mathrm{~A})$ between the setting levels. The lowest values were detectable at $80 \%$ lubricant dosage, which meant $1.12 \mathrm{~cm}^{3}$ per bores, for a total of $4.48 \mathrm{~cm}^{3}$ per tram. Differences between $20-80 \%$ mean a noise reduction of $6.5 \mathrm{~dB}(\mathrm{~A})$ for Tatra trams and $7.1 \mathrm{~dB}(\mathrm{~A})$ for CAF trams. 
In the absence of a test, values with a $100 \%$ setting were linearly predicted from the calculated results. Seeing the forecasted results and taking into account the operational aspects and considerations, it is not necessarily cost-effective to operate the rail lubrication devices at $100 \%$. Interestingly, an average of $3.5 \mathrm{~dB}(\mathrm{~A})$ can be found between the results of two trams, but the noise levels approached each other the most at a setting of $40 \%$. This may be explained by lower noise level of trams in presumably better condition that test day.

In addition to the noise measurement results, it is worth examining the changes in the friction coefficient and surface roughness of the rails as a result of lubrication, which are summarized in Table 3. However, interpretation of the results includes that the refinement of the surface roughness caused by grinding also caused a decrease in the values.

As the amount of grease increased, a decreasing trend in the results became detectable. The difference between the two rails is due to the curve, because the running plane of the trams is shifted on the rails. The results were also affected by significant lateral wear of the rails. Based on the values reported in the literature [8], the recorded results are adequate and ideal. Even with $80 \%$ lubricant dosing, the values could be considered safe, presumably acceptable values could have been measured even at maximum dosing. Compared to $20 \%$ lubrication, $80 \%$ halved the surface roughness values. As demonstrated in the table below, the largest decrease in friction coefficient values was measured on the surface of the left rail.

Table 3. Results of surface roughness and friction coefficient measurements

\begin{tabular}{|c|c|c|c|c|c|c|}
\hline \multirow{2}{*}{$\begin{array}{c}\text { Operation } \\
\text { of rail } \\
\text { lubrication } \\
\text { device }\end{array}$} & \multicolumn{3}{|c|}{ Left rail (inner) } & \multicolumn{3}{c|}{ Right rail (outer) } \\
\cline { 2 - 4 } & & \multicolumn{2}{|c|}{$\begin{array}{c}\text { Friction coefficient } \\
{[-]}\end{array}$} & & \multicolumn{2}{|c|}{$\begin{array}{c}\text { Friction coefficient } \\
\text { [-] }\end{array}$} \\
\cline { 2 - 7 } & $\mathbf{9 0}^{\circ}$ & $\mathbf{4 5}^{\circ}$ & & $\mathbf{9 0}^{\circ}$ & $\mathbf{4 5}^{\circ}$ \\
\hline $20 \%$ & 0.76 & 0.52 & 0.29 & 1.43 & 0.38 & 0.23 \\
\hline $40 \%$ & 0.60 & 0.40 & 0.29 & 1.04 & 0.35 & 0.24 \\
\hline $60 \%$ & 0.40 & 0.37 & 0.27 & 0.88 & 0.25 & 0.22 \\
\hline $80 \%$ & 0.30 & 0.27 & 0.23 & 0.63 & 0.34 & 0.18 \\
\hline
\end{tabular}


Considering the results of the noise measurements, as well as the surface roughness, and the friction coefficient, it can be said that the rail lubrication equipment is safe and recommended when operating at $80 \%$. Too much lubricant could result in unacceptably low friction coefficient, which is also supported by practical examples [17]. With the optimal setting, there are benefits during operation. Cost-effectiveness can be achieved by requiring fewer lubricant tanks to be replaced, less human resources for rail lubrication devices and, last but not least, trams being able to travel with guaranteed safety. If the rail lubrication device and its operating costs and the cost of rail replacement over a 5-10-year cycle are compared, the latter may be more worthwhile. To reduce maintenance costs, it is important to determine how much lubrication is required, there is an analysis [18] seeking an answer to this depending on the wear of the rails. Of course, it is also obvious from our results presented in this article that rail lubrication devices do not only play a role in reducing rail wear but at the same time they effectively mitigate noise.

\section{Conclusion}

The first set of noise measurements were performed in case of lubricated rails with corrugations, non-lubricated rails with corrugations, grinded rails as well as grinded and lubricated rails to determine the noise reduction efficiency of automated rail lubrication. However, the conducted tests and the recorded data allowed several conclusions to be drawn. Afterwards, 7 different types of lubricants were tested, where in addition to noise measurement the effect on braking was also examined. A number of previous conclusions were supported by the results obtained here. Finally, noise measurements were performed, and the value of the friction coefficient and rail roughness was examined by different dosage setting of a rail lubrication device.

- It can be concluded that lubrication and grinding have almost the same, but less than $5 \mathrm{~dB}(\mathrm{~A})$ noise reduction effect. However, appropriate and significant noise reduction values (which are results of $5 \mathrm{~dB}(\mathrm{~A})$ or above) have been achieved by grinding and rail lubrication together.

- Clearly, the highest noise reduction can be achieved by applying the lubrication and grinding together. Both methods combined are so effective that there is no significant difference $(1.6 \mathrm{~dB}(\mathrm{~A}))$ in resulting noise levels of the different types and ages of trams (Tatra, CAF). The examination of different lubricants also showed that the difference (deviation $1.3 \mathrm{~dB}(\mathrm{~A})$ ) in noise levels of trams (Tatra, CAF, Hanover) due to rail lubrication is minimal. 
- $\quad$ According to the results, noise reduction of 6.5-9.1 dB(A) for Tatra trams and 4.4-7.1 $\mathrm{dB}(\mathrm{A})$ for $\mathrm{CAF}$ trams was measurable, which, in addition to rail lubrication, are achieved by grinding as well as increasing the amount of lubricant.

- This study also confirms that grinding is one of the basic maintenance tasks, which - in addition to extending the life of the rails - results in noise reduction. In accordance with the expectations, the measurements support that the grinding improves the noise reduction of rail lubrication.

- General thesis is that the more lubricant is applied to the rails, the more effective noise reduction can be achieved. The delivery of the lubricants is limited by railway safety: the required braking distance of the trams must be ensured under all circumstances. As the amount of lubricant was increased, the coefficient of friction and rail roughness decreased. There was an average noise reduction of $2.3 \mathrm{~dB}(\mathrm{~A})$ between the setting levels.

- Based on the results of noise, friction coefficient and surface roughness measurements, the equipment operated with $80 \%$ lubricant application $\left(1.12 \mathrm{~cm}^{3}\right.$ per bores, for a total of $4.48 \mathrm{~cm}^{3}$ per tram) is suitable. The amount of lubricant (type of the examined grease) applied in this way is suitable for reducing unpleasant noise effect and providing the required braking distance for trams. The results of friction coefficient (0.18-0.34) under lubricated rails are in accordance with the values reported in the literature.

- Optimal noise reduction solution in small radius curves for newly built track: automated rail lubrication, for existing track: automated rail lubrication after elimination of rail surface defects. It is not necessary to operate the rail lubrication devices in Budapest with the maximum lubricant application, which can thus lead to a reduction in maintenance costs.

\section{Acknowledgement}

The authors are grateful to the staff of BKV Zrt., who provided the conditions for the measurements and helped us to conduct the tests. Special thanks to Tibor Ladányi for his help and work in the last measurements. The authors appreciate the help of colleagues from Metalelektro Measuring Technique Ltd. for their work with the TriboRoll device and for publishing the measurements results. 


\section{References}

[1] E. Juhász, Sz. Fischer, Tutorial on the fragmentation of the railway ballast particles and calibration methods in discrete element modelling, Acta Technica Jaurinensis 14 (2021) pp. 1-19. doi: https://doi.org/10.14513/actatechjaur. 00569

[2] B. Eller, Sz. Fischer, Tutorial on the emergence of local substructure failures in the railway track structure and their renewal with existing and new methodologies, Acta Technica Jaurinensis 14 (1) (2021) pp. 80-103. doi: https://doi.org/10.14513/actatechjaur. 00565

[3] D. Kurhan, The Mathematical Support of Machine Surfacing for the Railway Track, Acta Technica Jaurinensis 13 (3) (2020) pp. 246-267. doi: https ://doi.org/10.14513/actatechjaur.v13.n3.556

[4] D.J. Thompson, On the relationship between wheel and rail surface roughness and rolling noise, Journal of Sound and Vibration 193 (1) (1996) pp. 149160.

doi: https : //doi.org/10.1006/jsvi.1996.0254

[5] D.J. Thompson, B. Hemsworth, N. Vincent, Experimental validation of the TWINS prediction program for rolling noise, part 1: description of the model and method, Journal of Sound and Vibration 193 (1) (1996) pp. 123-135. doi: https://doi.org/10.1006/jsvi.1996.0254

[6] C. Esveld, Wheel-Rail Interface, in: C. Esveld (Ed.): Modern Railway Track, Digital Edition 2014, version 3.1, MRT-Productions, Zaltbommel, 2014, pp. 17-35.

[7] D. Thompson, Wheel/Rail Interaction and Excitation by Roughness, in: D. Thompson (Ed.), Railway Noise and Vibration: mechanism, modelling and means, 1st Edition, Elsevier Ltd., Oxford, 2009, pp. 127-173.

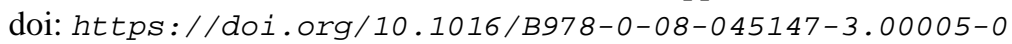

[8] U. Olofsson, R. Lewis, Tribology of the Wheel-Rail Contact, in: S. Iwnicki (Ed.), Handbook of Railway Vehicle Dynamics, CRC Press Taylor and Francis Group, LLC, Boca Raton, 2006, pp. 121-128. doi: https ://doi .org/10.1201/9781420004892

[9] M. Moreno-Ríos, E. A. Gallardo-Hernández et al., Field and laboratory assessments of the friction coefficient at a railhead, Proceedings of the Institution of Mechanical Engineers, Part F: Journal of Rail and Rapid Transit 230 (1) (2014) pp. 313-320. doi: https://doi.org/10.1177/0954409714536383 
[10] H. Chen, S. Fukagai et. al., Influence of leaves on the adhesion between wheel and rail, Quarterly Report of RTRI 59 (1) (2018) pp. 65-71. doi: https://doi.org/10.2219/rtriqr.59.1_65

[11] U. Olofsson, K. Sundvall, Influence of leaf, humidity and applied lubrication on friction in the wheel-rail contact: pin-on-disc experiments, Proceedings of the Institution of Mechanical Engineers, Part F: Journal of Rail and Rapid Transit 218 (3) (2004) pp. 235-242. doi: https://doi.org/10.1243/0954409042389364

[12] H. Chen, M. Ishida et. al., Estimation of wheel/rail adhesion coefficient under wet condition with measured boundary friction coefficient and real contact area, Wear 271 (1-2) (2011) pp. 32-39.

doi: $h t t p s$ ://doi .org/10.1016/j . wear . 2010.10.022

[13] Railway applications. Acoustics. Measurement of noise emitted by railbound vehicles, ISO 3095:2005 (2005).

[14] G. Csortos, F. Augusztinovicz, Noise mitigation with rail lubrication device on tramline, in: Prof Stjepan Lakušić (Ed.), Proceedings of the 5th International Conference on Road and Rail Infrastructure - CETRA 2018, University of Zagreb, Zagreb, 2018, pp. 1173-1179. doi: https://doi.org/10.5592/co/cetra.2018.745

[15] Investigation and rating of the environmental noise, MSZ 18150-1:1998 (1998) in Hungarian.

[16] T. Ladányi, Optimal setting of a rail lubrication equipment for noise reduction (in Hungarian: Sínkenő berendezés optimális beállítása a zajcsillapítás függvényében), MSc thesis, Széchenyi István University, Faculty of Architecture, Civil Engineering and Transport Science (2019).

[17] J. Lundberg, M. Rantatalo et al., Measurements of friction coefficients between rails lubricated with a friction modifier and the wheel of an IORE locomotive during real working conditions, Wear 324-325 (2015), pp. 109117.

doi: https://doi.org/10.1016/j.wear. 2014.12.002

[18] V. Reddy, G. Chattopadhyay, D. Hargreaves, Analysis of rail wear data for evaluation of lubrication performance, in: D. Hargreaves (Ed.) Proceedings of the 7th International Tribology Conference: AUSTRIB 2006: Putting Tribology to Work. AUSTRIB, CD Rom, 2006, pp. 1-8. 